CLINICAL STUDY

\title{
Effects of long-term continuous positive airway pressure on body composition and IGF1
}

\author{
Thomas Münzer ${ }^{1,2}$, Andrea Hegglin ${ }^{1,2}$, Tobias Stannek ${ }^{1,2}$, Otto D Schoch ${ }^{3}$, Wolfgang Korte ${ }^{4}$, Daniel Büche ${ }^{5}$, \\ Christoph Schmid ${ }^{6}$ and Christoph Hürny ${ }^{1,2}$ \\ ${ }^{1}$ Geriatrische Klinik, Kompetenzzentrum Gesundheit und Alter, Rorschacherstrasse 94, 9004 St Gallen, Switzerland, ${ }^{2}$ Geriatric University Hospital, Bern, \\ Switzerland, ${ }^{3}$ Multidisciplinary Sleep Center and Division of Pulmonary Medicine Kantonsspital, St Gallen, Switzerland, ${ }^{4}$ Institute for Clinical Chemistry \\ Kantonsspital, St Gallen, Switzerland, ${ }^{5}$ Bone Clinic Kantonsspital, St Gallen, Switzerland and ${ }^{6}$ Division of Endocrinology and Diabetes, Department of \\ Internal Medicine, University Hospital, Zürich, Switzerland
}

(Correspondence should be addressed to T Münzer at Geriatrische Klinik, Kompetenzzentrum Gesundheit und Alter; Email: thomas.muenzer@geriatrie-sg.ch)

\begin{abstract}
Objective: To investigate the long-term effects of nasal continuous positive airway pressure (CPAP) ventilation in patients with obstructive sleep apnea syndrome (OSAS) on body composition (BC) and IGF1.

Design: Observational study.

Subjects: Seventy-eight (11 females and 67 males) OSAS patients who were compliant with CPAP (age $51 \pm 1.1$ years) participated in the study. We assessed body mass index (BMI), total body mass (TBM), total body fat (TBF; $\mathrm{kg}$ ) and lean body mass (LBM; kg), abdominal subcutaneous (SC) and visceral (V) fat $\left(\mathrm{cm}^{2}\right)$, and waist circumference (WC; $\mathrm{cm}$ ) by magnetic resonance imaging, and IGF1 (ng/ml) before and after $7.8 \pm 1.3$ months of CPAP use of an average of $5.9 \pm 1.2 \mathrm{~h}$.

Results: Women had a higher BMI, WC; TBM, TBF, and more SC fat. Men had a higher LBM and more $\mathrm{V}$ fat. CPAP increased $\mathrm{WC}(+2.8 \pm 9.6 \mathrm{~cm}, P=0.02)$ and LBM $(2.2 \pm 0.5 \mathrm{~kg}, P=0.006)$, but not IGF1. In men, CPAP increased BMI $\left(0.5 \pm 0.2 \mathrm{~kg} / \mathrm{m}^{2}, P=0.02\right)$, WC $(1.7 \pm 6.9 \mathrm{~cm}, P=0.002)$, TBM $(1.7 \pm 0.4 \mathrm{~kg}, P=0.0001), \mathrm{LBM}(1.5 \pm 0.4 \mathrm{~kg}, P=0.0003), \mathrm{SC}$ fat $\left(12.9 \pm 5.1 \mathrm{~cm}^{2}, P=0.02\right)$, and IGF1 $(13.6 \pm 4.2 \mathrm{ng} / \mathrm{ml}, P=0.002)$.

Compliance with CPAP increased LBM in men aged $<60$ years, but not in those aged $>60$ years, and IGF1 increased in men aged 40-60 years only.

Conclusions: Long-term CPAP increased LBM in both sexes and IGF1 in men, while fat mass remained unchanged, suggesting a sexually dimorphic response of IGF1 to CPAP. The role of the GH axis activity and age to this response is unclear. The metabolic consequences of changes in LBM are still to be determined. Future studies on the effects of CPAP on BC should include LBM as an outcome.
\end{abstract}

European Journal of Endocrinology 162 695-704

\section{Introduction}

Obstructive sleep apnea syndrome (OSAS) is defined as repetitive decreases or cessations of airflow during sleep (1) and is associated with a wide array of cardiovascular (2) and metabolic risks $(3,4)$, and is therefore linked to an elevated cardiovascular morbidity and mortality. Interestingly, part of the risk profile appears to be shared by patients suffering from adult GH deficiency (GHD) syndrome (5). Additionally, OSAS has been associated with significant decreases in serum insulin-like growth factor 1 (IGF1) levels (6) and several metabolic disorders and alterations in body composition (BC) such as visceral (V) obesity (7). One possible explanation for the underlying mechanism in OSAS patients is the relative insensitivity of GHRH-induced GH response and a delayed IGF1 synthesis after GH injection in untreated disease (8). The physiologic release of $\mathrm{GH}$ in healthy humans is stimulated by GHRH as a function of sleep depth (9). Thus, continuous positive airway pressure (CPAP) therapy may lead to a restoration of the $\mathrm{GH}$ axis activity to a more physiological pattern, and consecutively affect BC $(6,10-12)$. Adipose tissue has been associated with most of the metabolic burden associated with $\operatorname{OSAS}(7,13,14)$, and short-term CPAP reduces $\mathrm{V}$ fat (15). However, to date, no study has examined the effects of CPAP ventilation on lean body mass (LBM), despite potential beneficial effects of such changes on body function. During normal aging, mean GH secretion decreases mainly due to diminished amplitude of spontaneous GH peaks, whereas peak frequency usually remains unchanged (16). Aging is also associated with decreased serum IGF1 levels, which correlate well with GH secretory peaks in both women 
and men (17-19). Several studies have demonstrated a significant relationship between a reduction of slow-wave sleep, decreased GH secretion rate, and peak amplitude in healthy aged individuals $(16,20)$, and that GH-releasing drugs can normalize sleep (21). Taken together, these data suggest that in addition to normal aging, sleep disturbances such as sleep apnea may substantially affect GH secretion and action, and thereby, have additional impact on the potential effects of CPAP treatment.

Several studies have reported a sexual dimorphic interaction of GH axis activation with sleep (22-24), and both GH administration to healthy old persons (25, 26) and GH therapy in patients with adult GHD syndrome (27) revealed that changes in LBM or adipose tissue depended on sex.

Based on the above findings, we hypothesized that long-term CPAP therapy would increase serum IGF1 levels in patients with OSAS, and that these changes would have been affected by the sex and the age of the patients. In addition, we examined the effects of CPAP on $\mathrm{BC}$ including total and regional fat tissues and LBM.

\section{Patient selection}

\section{Inclusion and exclusion criteria}

All women and men over the age of 18 years who were admitted as outpatients to the Kantonsspital, St Gallen, Interdisciplinary Center for Sleep Medicine between 01-01-2003 and 12-31-2005 for the evaluation of possible OSAS were invited to participate. Patients were usually referred by primary care physicians, pneumonologists, neurologists, and ear, nose and throat specialists. Patients with diabetes and hypercholesterolemia were included if they were on stable (oral) medication. There was no change in medication throughout the study period. Patients who participated in any other clinical study in the last 6 months prior to this protocol were excluded. In addition, we excluded women and men who were not able to complete German questionnaires without language support from their family members. Patients with pituitary disease, untreated thyroid disease, and medication known to interfere with the GH axis, and patients who had undergone elective surgery (such as gastric banding or hip replacement) within 6 months after enrollment were also not eligible. All patients were asked to maintain their diets and keep their level of physical activity constant during the study period. Written informed consent was obtained from all participants. The protocol had been approved by the St Gallen ethics committee.

Patients with possible OSAS were scheduled for an outpatient visit with one of the physicians in the sleep center. Prior to this appointment, all patients routinely completed a set of questionnaires. Covered domains were socio-demographic data, assessment of smoking status and alcohol use, a validated German version of the Epworth sleepiness scale (ESS) (28) and the Stanford Sleep Disorders Questionnaire (29). During the appointment, a complete medical history of each patient was obtained to assess comorbidities (30) such as hypertension, coronary heart disease, diabetes, hypercholesterolemia, and current medication. Physical examination included inspection of the oropharynx, auscultation of lungs and heart, and abdominal palpation, followed by a brief neurological examination. Based on clinical judgement and the results of these screening questionnaires, patients who had a high likelihood to have OSAS were then scheduled for polysomnography (PSG). In the evening preceding PSG, patients were admitted to the sleep center. They were then asked to participate in the study. In the morning after the sleep study, after an overnight fast, blood samples for baseline measurements including IGF1 were drawn, independent of the result of the sleep study. Patients with OSAS who agreed to begin with CPAP were scheduled for baseline BC examination before or during a 2-week time period after initiation of CPAP therapy. Patients received an instruction in nasal CPAP ventilation followed by home CPAP. Monitoring of hours of operation of the CPAP machine was used as a measure of compliance. After at least 6 months of CPAP ventilation, all baseline examinations were repeated.

\section{Materials and methods}

\section{Polysomnography}

PSG data were recorded with a commercially available monitoring system (Mepal, MAP Medizin-Technologie, Martinsried, Germany). In the evening preceding the sleep study, each participant was offered a standardized meal at $1800 \mathrm{~h}$. Lights were turned off at $2200 \mathrm{~h}$. Minimum recording time was $6 \mathrm{~h}$ in order to meet diagnostic standards. All sleep studies were analyzed by an experienced physician. Respiration was traced with nasal pressure prongs and by piezoelectric thoracic and abdominal effort bands. Main outcome variables for the diagnosis of OSAS were apnea-hypopnea index (AHI) defined as the number of apneas $(>80 \%$ reduction of the flow signal) and hypopneas ( $>50 \%$ reduction of the flow signal) per hour of sleep monitored and the desaturation index defined as the hourly rate of episodes of arterial oxygen desaturations $>3 \%$ of the stable baseline. The severity of sleep apnea was graded as mild (5-15 events per hour), moderate (16-30 events per hour), and severe ( $>30$ events per hour) (1). Depending on the results of this analysis, the patients were advised to commence with CPAP instruction followed by continuous home ventilation. 


\section{Nasal CPAP ventilation and assessment of compliance}

Patients who were eligible for ventilation were instructed by trained nurses in the sleep center. Effectiveness of ventilation was monitored by changes in clinical symptoms, nocturnal oxygen saturation $\mathrm{SaO}_{2}$ recordings, and an automated CPAP titration device (Sullivan Autoset T, ResMed Corp., San Diego, CA, USA). After a period of three overnight stays in the unit, patients were discharged for home ventilation. As an estimate of compliance with the CPAP machine over the entire study period, we recorded the mean hours of operation per night during 6 months of CPAP use. Ambulatory overnight oximetry (Konica-Minolta Pulsox 3, Dietikon, Switzerland) was used to measure changes of oxygen saturation while ventilated at home. In addition, one single experienced pulmonologist (O D S) reviewed all patient charts and oximetry results. Based on clinical follow-up information, overnight oximetry data, and chart information, patients were graded into two categories: non-compliant and well-compliant. We defined an average of $\geq 4 \mathrm{~h}$ of CPAP use per night as a minimum requirement to classify a patient as compliant (31).

\section{Clinical assessment of BC}

Weight was measured to the nearest $0.1 \mathrm{~kg}$ on a calibrated scale, and height was determined using a wall-mounted stadiometer. Body mass index (BMI) was calculated as the weight divided by the square of height $\left(\mathrm{kg} / \mathrm{m}^{2}\right)$.

\section{Imaging studies for the assessment of BC}

In each study participant, a dual energy X-ray absorptiometry (DEXA) determination of LBM and total and relative fat mass was performed. DEXA assessment was performed by one single experienced technician at the Kantonsspital, St Gallen, Bone Clinic with a commercially available scanner (Lunar DPX-NT, Lunar, General Electrics Healthcare, Munich, Germany). We used the scanner-installed software package (Encore Version 6.7, General Electrics Healthcare, Munich, Germany). The subjects were measured in light clothing. The scanner was calibrated every morning and three times a week; a bone phantom scan was used to determine scan quality. Internal calibration demonstrated a coefficient of variation of $0.16 \%$. This method has been shown to precisely assess BC in several research settings $(32,33)$. Patients underwent magnetic resonance imaging (MRI) at the level of L4/5 for the assessment of abdominal subcutaneous (SC) and V fat areas. Abdominal MRI examinations were performed on a $1.5 \mathrm{~T}$ clinical imaging system (Symphony, Siemens, Munich, Germany, software version Syngo MR2004A4VA25A). Patients were scanned in the non-fasting state in supine position using breath-holding technique and a $\mathrm{T}_{1}$, flash-2D sequence set to optimize fat bright signal versus intermediate to dark signal adjacent tissues. Image matrix size was adapted to scan the greatest area possible. Slice thickness was $8 \mathrm{~mm}$ with an interslice gap of $100 \%$. Images were analyzed on a PC using ImageJ, an NIH-developed analyzing software (Rasband, WS, ImageJ, USA National Institutes of Health, Bethesda, MD, USA, http://rsb.info.nih. gov/ij/, 1997-2006), as described previously (34).

\section{Serum IGF1}

After the sleep study and at follow-up, after an overnight fast, blood samples were drawn from an antecubital vein. After centrifugation, serum aliquots were stored at $-80{ }^{\circ} \mathrm{C}$, and then sent to the Research Laboratory of the Division of Endocrinology at the University of Zürich for measurements of IGF1 levels. IGF-binding proteins were removed by acid Sep-Pak chromatography according to the instructions of the supplier (Waters Associates, Milford, MA, USA), and IGF1 was determined by RIA $(35,36)$. All samples were analyzed in a single batch by a technician who was not aware of any study data.

\section{Data management and statistical analyses}

Analyses were done with Stata (Stata Corp. 2005. Stata Statistical Software: Release 9, College Station, TX, USA). Summary statistics are described as means, medians, and s.E.M.s of the mean (s.E.M). Baseline associations were calculated by simple linear regression. We first analyzed overall changes in the respective outcome parameters, followed by analyses for changes in non-compliant and compliant patients respectively. To examine possible sex and age effects, the compliant group was grouped by sex, and men were categorized based on the age at study entry $(\leq 40,40-60$, and $>60$ years). Subsequent statistical analyses were performed in each age category separately. Differences between categorical variables within each age or sex group were assessed by $\chi^{2}$ tests, and differences between continuous variables were calculated with Mann-Whitney tests or $t$-tests where appropriate. In addition, we applied ANOVA to detect possible differences between age categories at baseline. Contributions of baseline factors to changes of outcome variables of interest were entered into a stepwise linear regression model. A $P$ value of $<0.05$ was considered as significant.

\section{Results}

\section{Patients}

Of 566 patients screened for participation, 101 patients were excluded due to language barriers. In total, 198 patients did not give informed consent for personal and work-related reasons (difficulty in leaving the job for 
additional study appointments). Non-consenters and consenters did not differ by age, sex, BMI, smoking status, and socio-demographic data; however, consenters more often reported alcohol use $(215 / 260,82.7$ vs $143 / 192,74.5 \%, P=0.03)$ and had a slightly higher mean ESS score $(11.3 \pm 4.4$ vs $10.6 \pm 4.8, P=0.03$; data not shown). Using disease categories provided in the Charlson comorbidity index (30), we found an increased prevalence of chronic obstructive pulmonary disease in patients who were $>60$ years of age and no additional associations of age with other chronic diseases. Eight patients with diabetes on regular oral medication (sulfonylurea or metformin) were included. Patients were equally distributed between severity and age categories ( $\chi^{2}$ test $P=0.4$, data not shown). Here, we report data on changes in $\mathrm{BC}$ in 78 patients (11 women and 67 men) who were compliant and in 35 patients who were non-compliant with ventilation for a period of at least 6 months. For 73 of them (56 compliant), complete data sets of serum IGF1 were available (Fig. 1, Tables 1 and 2).

\section{Baseline characteristics of study population}

At baseline, compliant and non-compliant patients were not statistically different regarding age, waist

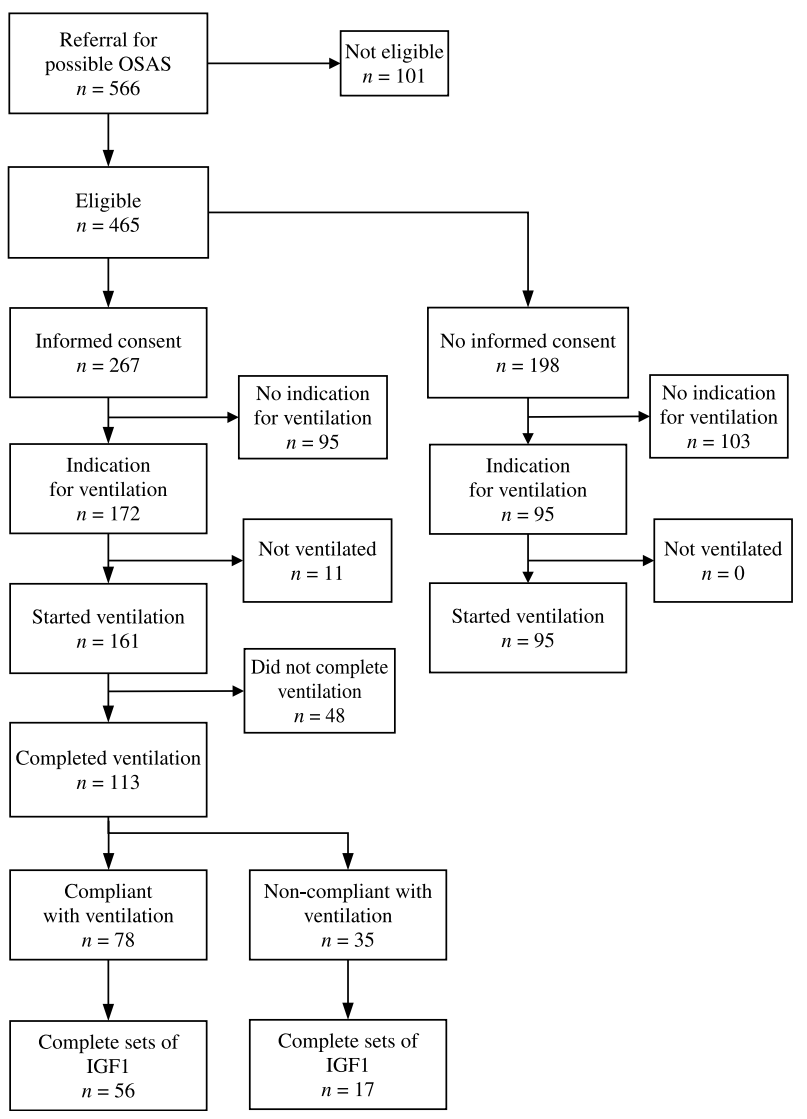

Figure 1 Study flow. circumference (WC), BMI, total body mass (TBM), LBM, TFM, SC fat, V fat, and IGF1 levels, and compliance did not differ between age categories (data not shown). However, non-compliant patients had a lower AHI (difference $-13.8 \pm 5.7, P=0.02$ ). We studied 11 compliant women and five women who were not compliant with CPAP use. Using $\chi^{2}$ analysis, women were evenly distributed among age and compliance groups $(P=0.41$; Table 1$)$.

Compliant women and men did not differ by age, TBM, V fat, and baseline IGF1. In contrast women had a higher BMI $(+5.0 \pm 1.6, P=0.003)$, a higher WC $(+8.6 \pm 2.8 \mathrm{~cm}, P=0.004)$, less LBM $(-12.3$ $\pm 2.4 \mathrm{~kg}, P=0.000001)$, more total body fat (TBF) $(+21.4 \pm 3.3 \mathrm{~kg}, P=0.000001)$, and more SC fat $\left(+188.9 \pm 26 \mathrm{~cm}^{2}, P=0.000001\right)$.

\section{Baseline serum IGF1}

There was no sex difference between serum IGF1 levels at baseline and at follow-up. Thus, IGF1 data were pooled for analysis. IGF1 levels tended to be higher in non-compliant patients, but levels did not differ among age or compliance groups at baseline, and we found no correlation of age with IGF1 (data not shown; Table 1).

\section{Baseline associations of IGF1 and LBM with OSAS severity}

At baseline, we found no significant correlations of IGF1 with TBM, TBF, LBM, or AHI, neither overall nor across or within age categories. In addition, we found no associations of LBM with AHI or with IGF1 overall or across age categories (data not shown).

\section{Effects of CPAP on BC and IGF1 levels in non-compliant patients}

Patients underwent effective (nightly usage $\geq 4 \mathrm{~h}$, mean $5.5 \pm 1.2 \mathrm{~h}$ ) CPAP ventilation therapy over a period of $7.8 \pm 1.3$ months. In contrast, non-compliant patients used the machine for an average of $2.4 \pm 0.2 \mathrm{~h}$ per night $(P=0.00001)$. In non-compliant patients, WC increased by $+2.7 \pm 7.3 \mathrm{~cm}(P=0.002)$ and BMI by $0.5 \pm 0.3 \mathrm{~kg} / \mathrm{m}^{2} \quad(P=0.004)$. In addition, TBM increased $(+1.8 \pm 0.7 \mathrm{~kg}, P=0.01)$, and LBM $(1.3$ $\pm 0.7 \mathrm{~kg}, P=0.07)$ and TFM $(+0.6 \pm 0.8 \mathrm{~kg}, P=0.5)$ remained unchanged. Abdominal SC fat increased by $19 \pm 9 \mathrm{~cm}^{2}(P=0.047)$ and $V$ fat by $12.3 \pm 15.6 \mathrm{~cm}^{2}$ $(P=0.4)$. Serum IGF1 levels increased by +3.2 $\pm 8.4 \mathrm{ng} / \mathrm{ml}(P=0.7$; Table 2$)$.

\section{Effects of CPAP on BC and serum IGF1 levels in compliant patients by sex}

After almost 8 months of CPAP use, we found overall increases in BMI $\left(0.5 \pm 0.2 \mathrm{~kg} / \mathrm{m}^{2}, P=0.006\right)$ and WC $(+1.9 \pm 0.6 \mathrm{~cm}, \quad P=0.002)$, and of SC fat 
Table 1 Baseline characteristics of 35 non-compliant and 78 compliant patients with continuous positive airway pressure (CPAP; means \pm S.E.M).

\begin{tabular}{|c|c|c|c|c|c|c|c|c|c|c|}
\hline \multirow[b]{3}{*}{ Age (years) } & \multicolumn{3}{|c|}{ Non-compliant } & \multicolumn{3}{|c|}{ Compliant women } & \multicolumn{3}{|c|}{ Compliant men } & \multirow{3}{*}{$\begin{array}{c}\text { Sex difference } \\
\frac{P}{0.5}\end{array}$} \\
\hline & \multirow{2}{*}{$\begin{array}{c}\begin{array}{c}\text { All } \\
(n=35)\end{array} \\
52.1\end{array}$} & \multicolumn{2}{|c|}{ Range } & \multirow{2}{*}{$\begin{array}{c}\begin{array}{c}\text { Mean } \\
(n=11)\end{array} \\
51.2\end{array}$} & \multicolumn{2}{|c|}{ Range } & \multirow{2}{*}{$\begin{array}{c}\begin{array}{c}\text { Mean } \\
(n=67)\end{array} \\
50.8\end{array}$} & \multicolumn{2}{|c|}{ Range } & \\
\hline & & 19.8 & 76.9 & & 37.6 & 70.7 & & 27.2 & 77.5 & \\
\hline $\mathrm{AH} \mathrm{I}^{\mathrm{a}}$ & $32.5^{\star}$ & 8.4 & 109.0 & 46.3 & 7.5 & 95.7 & 49.4 & 7.1 & 109.0 & 0.1 \\
\hline $\mathrm{BMI}^{\mathrm{b}}$ & 30.4 & 23.8 & 39.7 & 30.9 & 26.2 & 43.4 & 30.0 & 22.1 & 41.7 & 0.004 \\
\hline Waist circumference $(\mathrm{cm})$ & 103.9 & 88.8 & 127.4 & 104.1 & 93.5 & 119.0 & 102.7 & 87.3 & 120.6 & 0.004 \\
\hline Total body mass $(\mathrm{kg})$ by DEXA ${ }^{\mathrm{c}}$ & 89.1 & 71.7 & 126.2 & 90.5 & 71.7 & 114.6 & 89.4 & 70.8 & 130.8 & 0.0003 \\
\hline Lean body mass $(\mathrm{kg})$ by DEXA & 55.6 & 38.5 & 75.9 & 56.7 & 39.7 & 50.7 & 58.3 & 45.4 & 75.2 & 0.000001 \\
\hline Total fat mass $(\mathrm{kg})$ by DEXA & 30.5 & 20.9 & 50.4 & 49.5 & 29.4 & 61.5 & 28.1 & 15.5 & 55.6 & 0.000001 \\
\hline Abdominal subcutaneous fat $\left(\mathrm{cm}^{2}\right)$ & 243.3 & 137.9 & 405.3 & 415 & 268.6 & 546.3 & 226 & 124.0 & 516.0 & 0.000001 \\
\hline Abdominal visceral fat by $\mathrm{MRI}\left(\mathrm{cm}^{2}\right)$ & 211.3 & 72.1 & 367.4 & 163 & 69.3 & 273.1 & 210 & 60.2 & 443.3 & 0.1 \\
\hline IGF1 (ng/ml) & 130.5 & 67.0 & 300.0 & 124.0 & 56.0 & 235.0 & 115.1 & 44.0 & 241.0 & 0.6 \\
\hline Average CPAP use per night & $2.5^{\dagger}$ & 0.2 & 3.9 & 6.0 & 4.0 & 8.0 & 5.9 & 4.0 & 8.8 & 0.1 \\
\hline
\end{tabular}

${ }^{\star} P=0.02,{ }^{\dagger} P=0.0001$. Bold indicates $P<0.05$.

apnea-hypopnea index.

body mass index.

${ }^{\mathrm{c} D u a l}$ energy X-ray absorptiometry.

$\left(+15 \pm 5 \mathrm{~cm}^{2}, P=0.008\right)$. In addition, TBM $(+1.7$ $\pm 0.4 \mathrm{~kg}, \quad P=0.00001), \quad$ LBM $\quad(+1.6 \pm 2.5 \mathrm{~kg}$, $P=0.00001)$, and serum IGF1 $(+10.6 \pm 4 \mathrm{ng} / \mathrm{ml}$, $P=0.01)$ increased significantly, and there were no changes in TBF, $\mathrm{V}$ fat, or BMI respectively. In compliant women, CPAP increased $\mathrm{WC}(+2.8 \pm 9.6 \mathrm{~cm}, P=0.02)$ and LBM $(+2.2 \pm 0.5 \mathrm{~kg}, P=0.006)$ only. In compliant men, CPAP affected BMI $\left(0.5 \pm 0.2 \mathrm{~kg} / \mathrm{m}^{2}, P=0.02\right)$, WC $(1.7 \pm 0.7 \mathrm{~cm}, P=0.02)$, TBM $(1.7 \pm 0.4 \mathrm{~kg}, P=0.001)$, and LBM $(1.5 \pm 0.4 \mathrm{~kg}, P=0.003)$. Furthermore, $\mathrm{SC}$ fat $\left(+12.9 \pm 5.1 \mathrm{~cm}^{2}, \quad P=0.02\right)$ and IGF1 $(+13.6$ $\pm 4.2 \mathrm{ng} / \mathrm{ml}, P=0.002$ ) increased after CPAP (Table 2).

\section{Effects of nCPAP on BC and serum IGF1 levels in compliant men by age}

In men aged $<40$ years, BMI $\left(+1.0 \pm 0.4 \mathrm{~kg} / \mathrm{m}^{2}\right.$, $P=0.02)$, TBM $(+3.4 \pm 1.2 \mathrm{~kg}, P=0.02)$, and $\mathrm{LBM}$ $(+3.0 \pm 1.0 \mathrm{~kg}, \quad P=0.02)$ but not IGF1 $(+23.0$ $\pm 12.3 \mathrm{ng} / \mathrm{ml}, P=0.1$ ) increased significantly, and there was a trend toward an increase in WC $(P=0.07)$. In patients aged 40-60 years, TBM $(+1.0 \pm 0.5 \mathrm{~kg}, \quad P=0.03), \quad$ LBM $\quad(+1.0 \pm 0.4 \mathrm{~kg}$, $P=0.02)$, and IGF1 $(+12.6 \pm 5.3 \mathrm{ng} / \mathrm{ml}, P=0.02)$ increased significantly. In men aged 60 years and older, we found a significant increase in TBM $(+2.3 \pm 0.8 \mathrm{~kg}, \quad P=0.01)$ and a trend toward an increase in BMI, but no changes in other measures of $\mathrm{BC}$ or IGF1 levels.

\section{Stepwise multiple linear regression of changes in IGF1 and $L B M$ in compliant men}

Using stepwise multiple regression analysis in men with changes in IGF1 (Model 1) or changes in LBM (Model 2) as dependent variables and changes in $\mathrm{BC}$, age at baseline, and hours of ventilation as independent variables, we found no statistically significant model. However, hours of ventilation best predicted changes in LBM and IGF1 respectively.

\section{Discussion}

In this non-randomized prospective trial in patients diagnosed with sleep apnea syndrome, we found that compliance with CPAP over a period of 8 months significantly increased LBM in woman and men, and that IGF1 increased in men only. Overall, we observed small increases in WC and SC fat in all groups, despite compliance with ventilation. In contrast, in noncompliant patients, LBM remained unchanged. Serum IGF1 levels increased in compliant men, but not in women or in non-compliant patients.

Several groups have reported associations of OSAS with fat tissue as a dependent $(7,14,37)$ or an independent $(38,39)$ metabolic risk factor. A previous study reported reductions of $\mathrm{V}$ fat areas after 3 months of CPAP ventilation in a cohort of men aged 50 years with a very high AHI (15). We found small increases in abdominal SC fat and WC but not in V fat using a different imaging method in a mixed patient population with a wider age range treated over a longer time period. Nevertheless, increases in WC of $1.9 \mathrm{~cm}$ overall in association with respective changes in SC fat warrant further discussion.

Anthropometric measures of obesity often predict the prevalence of sleep apnea. Especially, WC is a reliable predictor of OSAS severity $(40,41)$ and a clinically well-known parameter to assess the metabolic syndrome (42). Therefore, treatment with CPAP could be associated with a reduction in WC. Contrary to such an expectation, we found significant increases in SC fat and WC and very small increases in TBF, while TBM remained almost constant over the 8 months of 


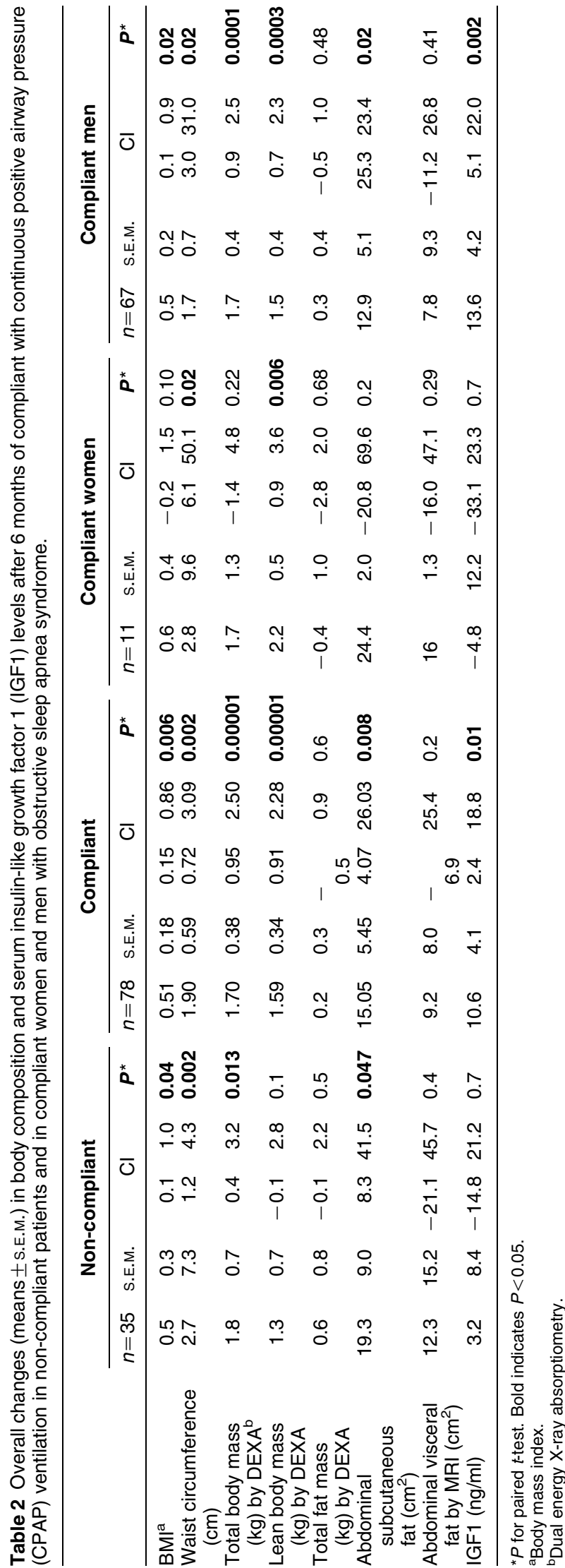

ventilation. It is currently unclear if such changes impact upon the metabolic burden of OSAS patients, since several alterations associated with this disease are independent of fat tissues $(12,39)$. Apparently, the effects of CPAP on BC in OSAS are distinct from the effects of GH in GHD, where TBF is usually decreased, in addition to an increase in IGF1 and LBM.

Although fat tissue is of clinical importance in patients with sleep apnea, the effects of CPAP use on LBM have not been examined. In man, the impact of muscle mass and exercise on glucose uptake has been known for a long time (43), and numerous studies have confirmed the roles of skeletal muscle, its oxidative capacity, and energy expenditure (EE) on insulin sensitivity, strongly supporting the role of LBM in glucose metabolism. We have recently reported that CPAP ventilation significantly improved maximal exercise capacity and heart rate recovery in our patients (44), a finding that is in line with an earlier report on the effects of 4 weeks of CPAP treatment on endurance exercise performance (45). Taken together, such data suggest that both the increases in LBM and the improvement in $\mathrm{VO}_{2}$ max reflect changes with the potential to increase exercise performance and to decrease the metabolic and cardiovascular risks of OSAS patients.

The mechanisms by which CPAP affects LBM are currently unknown. First, ventilated patients report less daytime sleepiness and more vitality (46), which may impact upon their level of physical activity and protect against the disease (47). In addition, physical activity augments GH axis activity in young and to a lesser extent in older persons $(48,49)$. Thus, exercise-induced increases in GH axis activity may have additional beneficial effects on LBM. In order to control for such an effect, we have asked our patients to not change their levels of exercise or their diets during the study period. However, our protocol did not record daily activities or diets, which seemed not to be feasible for such a long study period and the clinical design. Another factor contributing to changes in BC after CPAP use is EE. Several studies have demonstrated that resting EE is closely associated with OSAS and disease severity respectively $(50,51)$, and one previous report demonstrated that EE is increased during sleep in OSAS patients, and that CPAP decreases EE and by this mechanism induces body weight (52) and possibly also LBM.

In contrast to healthy young or older individuals, we found no significant correlations of IGF1 with measures of body fat (53) or age (19) in our patients at baseline. These findings suggest a disruption of the GH-IGF1 axis activity based on a change in regular sleep pattern with this disease (54), or that this could be an effect of the small sample size. Although 1 month of sham ventilation induced elevated IGF1 levels (55), normalization of sleep pattern induced a restoration of the $\mathrm{GH}$ axis activity. Three days of CPAP ventilation induced increases in GH secretion (10), and IGF1 levels 
increased after 3 months of CPAP use (6). The latter group also found an age-dependent response of IGF1 to CPAP (6). Given the fact that normal aging is associated with a decrease in GH secretion (17), the above and our results suggest that the IGF1 response to 8 months of CPAP use may also be attenuated with advanced age. Similarly, we observed increases in IGF1 and LBM in middle-aged men but not in older or younger men. The latter finding can be explained by the small number of men studied. Nevertheless, such a pattern is congruent with a reduced response in LBM after the administration of GH to healthy older individuals (56) when compared with young patients with adult GHD syndrome (57-59).

Serum IGF1 concentrations after CPAP remained unchanged in our women. While these results should be interpreted with some caution due to the small sample size, current findings suggest that GHRH impairs sleep in women (22), and that the $\mathrm{GH}$ secretagogue ghrelin improves sleep in young and older men $(60,61)$ but not in women, suggesting a sexually dimorphic response of sleep to hormone administration. While CPAP is known to decrease ghrelin in men (62), data on women are missing. Otherwise, normalization of sleep pattern by CPAP might impact upon GH secretion and IGF1 synthesis in women and men differently. Based on these observations, our data suggest that long-term CPAP activates the $\mathrm{GH}$ axis, and that such changes are gender dependent.

Our study has several limitations. First, our design did not allow for a true control group. Thus, the effects of CPAP on groups are comparable only to a limited extent, and the current design allows hypothesis generation rather than hypothesis testing. This is especially true for the hypothesis of a possible dose-response relationship between CPAP and changes in $\mathrm{BC}$, since the primary treatment goal of CPAP is elimination of obstructive events. Nevertheless, our regression model suggested that the duration of ventilation is a potential predictor for changes in LBM. In addition, we did not record the menopausal status of our women. Postmenopausal status is associated with an increased prevalence of sleep-disordered breathing $(63,64)$, and circulating progesterone protects against dilation of the upper airway muscles (65). In our study, women were evenly distributed among age and compliance groups, which attenuated the effect of menopause on our results.

We were also not able to randomize patients into a placebo ventilation group, although such studies have demonstrated an improvement in function (66), endocrine axis activity (55), or control of diabetes (67). Given the study duration of at least 6 months and the high risk for cardiac events in untreated patients (68), it seemed unethical to not offer treatment for such a long period. Secondly, we were able to recruit only small numbers of patients into the respective study groups. This might have affected our results. In addition, we were not able to demonstrate direct effects of CPAP ventilation on $\mathrm{GH}$ axis activity by frequent $\mathrm{GH}$ sampling. Given the diminished $\mathrm{GH}$ response to stimulation in untreated patients with OSAS (8), it seems comprehensible that ventilation would induce a more ordered 24-h GH secretion. Our study was primarily focused on changes in BC. We thus did not record changes in other clinically important measures such as blood pressure, which has been shown to decrease in several trials (69-71). Finally, using a prepost design, we were able to detect changes within specific age categories only. This approach does not allow for inferring a direct effect of age on the main outcome variable. To approach such an effect, a regression model with a larger number of data points would have been more appropriate. However, we think that our study allows the hypothesis that CPAP treatment affects LBM by several mechanisms, one being the restoration of the $\mathrm{GH}$ axis activity and, furthermore, that this effect might be influenced by the age of the patients.

In summary, the results of our study suggest that an average of 8 months of CPAP ventilation in patients with newly diagnosed OSAS significantly increases LBM in women and men. The observed changes in IGF1 suggest a sexual dimorphic response pattern of $\mathrm{GH}$ secretion after CPAP therapy. Future studies on BC in OSAS patients should include LBM as a clinical outcome parameter. Given the increasing prevalence of sleepdisordered breathing in a growing number of older persons $(64,72)$ and the small number of women studied with this disease, additional trials on the effects of CPAP ventilation in women or in persons with advanced age are warranted.

\section{Declaration of interest}

The authors declare that there is no conflict of interest that could be perceived as prejudicing the impartiality of the research reported.

\section{Funding}

This study was funded by the Swiss National Science Foundation (SNF) Grant Number: 3200-068115 to T Münzer, C Hürny, and O D Schoch, and was registered in 2003 at the SNF website (www.snf.ch).

\section{Acknowledgements}

We thank Sandro Pampallona, Formed (Statistics for Medicine) Evolène, for his important statistical comments on the manuscript and his engagement in the study design, power calculation, and the design of the database. We also appreciate the technical expertise and the assistance of C Zwimpfer, Division of Endocrinology and Diabetes, Department of Internal Medicine, University Hospital, Zurich, with the performance of the IGF1 assays. In addition, we thank Monika Diethelm for her flexibility and the skilled performance of the DEXA scans, the staff of the Kantonsspital St Gallen Center for Sleep Medicine for the support with recruitment, and Drs Ullmer, Knoblauch, Nierhoff, and Paky for the clinical assessment of the patients. Dr Münzer was supported by a Forschungskolleg Geriatrie Grant of the Robert Bosch Foundation, Stuttgart, Germany. We thank Dr Robert Thurnheer for his constructive critique of the manuscript. 


\section{References}

1 Flemons WW, Buysse D, Redline S, Pack A, Strohl K, Wheatley J, Young T, Douglas N, Levy P, McNicholas W, Fleetham J, White D, Schmidt-Nowarra W, Carley D \& Romaniuk J. Sleep-related breathing disorders in adults: recommendations for syndrome definition and measurement techniques in clinical research. The Report of an American Academy of Sleep Medicine Task Force. Sleep 199922 667-689.

2 Elmasry A, Lindberg E, Berne C, Janson C, Gislason T, Awad Tageldin M \& Boman G. Sleep-disordered breathing and glucose metabolism in hypertensive men: a population-based study. Journal of Internal Medicine 2001249 153-161.

3 Vgontzas AN, Bixler EO \& Chrousos GP. Sleep apnea is a manifestation of the metabolic syndrome. Sleep Medicine Reviews 20059 211-224.

4 Punjabi NM \& Polotsky VY. Disorders of glucose metabolism in sleep apnea. Journal of Applied Physiology $2005991998-2007$.

5 Jorgensen JO, Muller J, Moller J, Wolthers T, Vahl N, Juul A, Skakkebaek NE \& Christiansen JS. Adult growth hormone deficiency. Hormone Research 199442 235-241.

6 Grunstein RR, Handelsman DJ, Lawrence SJ, Blackwell C, Caterson ID \& Sullivan CE. Neuroendocrine dysfunction in sleep apnea: reversal by continuous positive airways pressure therapy. Journal of Clinical Endocrinology and Metabolism 198968 352-358.

7 Vgontzas AN, Bixler EO \& Chrousos GP. Metabolic disturbances in obesity versus sleep apnoea: the importance of visceral obesity and insulin resistance. Journal of Internal Medicine 2003254 32-44.

8 Gianotti L, Pivetti S, Lanfranco F, Tassone F, Navone F, Vittori E, Rossetto R, Gauna C, Destefanis S, Grottoli S, De Giorgi R, Gai V, Ghigo E \& Maccario M. Concomitant impairment of growth hormone secretion and peripheral sensitivity in obese patients with obstructive sleep apnea syndrome. Journal of Clinical Endocrinology and Metabolism 200287 5052-5057.

9 Van Cauter E \& Plat L. Physiology of growth hormone secretion during sleep. Journal of Pediatrics 1996128 S32-S37.

10 Cooper BG, White JE, Ashworth LA, Alberti KG \& Gibson GJ. Hormonal and metabolic profiles in subjects with obstructive sleep apnea syndrome and the acute effects of nasal continuous positive airway pressure (CPAP) treatment. Sleep 199518 172-179.

11 Saini J, Krieger J, Brandenberger G, Wittersheim G, Simon C \& Follenius M. Continuous positive airway pressure treatment. Effects on growth hormone, insulin and glucose profiles in obstructive sleep apnea patients. Hormone and Metabolic Research 199325 375-381.

12 McArdle N, Hillman D, Beilin L \& Watts G. Metabolic risk factors for vascular disease in obstructive sleep apnea: a matched controlled study. American Journal of Respiratory and Critical Care Medicine $2007 \mathbf{1 7 5}$ 190-195.

13 Schafer H, Pauleit D, Sudhop T, Gouni-Berthold I, Ewig S \& Berthold HK. Body fat distribution, serum leptin, and cardiovascular risk factors in men with obstructive sleep apnea. Chest 2002 122 829-839.

14 Vgontzas AN, Papanicolaou DA, Bixler EO, Hopper K, Lotsikas A, Lin HM, Kales A \& Chrousos GP. Sleep apnea and daytime sleepiness and fatigue: relation to visceral obesity, insulin resistance, and hypercytokinemia. Journal of Clinical Endocrinology and Metabolism 200085 1151-1158.

15 Chin K, Shimizu K, Nakamura T, Narai N, Masuzaki H, Ogawa Y, Mishima M, Nakao K \& Ohi M. Changes in intra-abdominal visceral fat and serum leptin levels in patients with obstructive sleep apnea syndrome following nasal continuous positive airway pressure therapy. Circulation 1999100 706-712.

16 van Coevorden A, Mockel J, Laurent E, Kerkhofs M, L’HermiteBaleriaux M, Decoster C, Neve P \& Van Cauter E. Neuroendocrine rhythms and sleep in aging men. American Journal of Physiology 1991260 E651-E661.

17 Corpas E, Harman SM \& Blackman MR. Human growth hormone and human aging. Endocrine Reviews $19931420-39$.
18 Hindmarsh PC, Dennison E, Pincus SM, Cooper C, Fall CH, Matthews DR, Pringle PJ \& Brook CG. A sexually dimorphic pattern of growth hormone secretion in the elderly. Journal of Clinical Endocrinology and Metabolism $1999842679-2685$.

19 O'Connor KG, Tobin JD, Harman SM, Plato CC, Roy TA, Sherman SS \& Blackman MR. Serum levels of insulin-like growth factor-I are related to age and not to body composition in healthy women and men. Journals of Gerontology. Series A, Biological Sciences and Medical Sciences 199853 M176-M182.

20 Van Cauter E, Leproult R \& Plat L. Age-related changes in slow wave sleep and REM sleep and relationship with growth hormone and cortisol levels in healthy men. Journal of the American Medical Association $2000 \mathbf{2 8 4} 861-868$.

21 Chapman IM, Bach MA, Van Cauter E, Farmer M, Krupa D, Taylor AM, Schilling LM, Cole KY, Skiles EH, Pezzoli SS, Hartman ML, Veldhuis JD, Gormley GJ \& Thorner MO. Stimulation of the growth hormone $(\mathrm{GH})$-insulin-like growth factor-1 axis by daily oral administration of a GH secretogogue (MK-677) in healthy elderly subjects. Journal of Clinical Endocrinology and Metabolism 199681 4249-4257.

22 Mathias S, Held K, Ising M, Weikel JC, Yassouridis A \& Steiger A. Systemic growth hormone-releasing hormone (GHRH) impairs sleep in healthy young women. Psychoneuroendocrinology 200732 1021-1027.

23 Schussler P, Yassouridis A, Uhr M, Kluge M, Weikel J, Holsboer F \& Steiger A. Growth hormone-releasing hormone and corticotropinreleasing hormone enhance non-rapid-eye-movement sleep after sleep deprivation. American Journal of Physiology. Endocrinology and Metabolism 2006291 E549-E556.

24 Latta F, Leproult R, Tasali E, Hofmann E, L'Hermite-Baleriaux M, Copinschi G \& Van Cauter E. Sex differences in nocturnal growth hormone and prolactin secretion in healthy older adults: relationships with sleep EEG variables. Sleep $2005 \mathbf{2 8}$ 1519-1524

25 Münzer T, Rosen CJ, Harman SM, Pabst KM, St Clair C, Sorkin JD \& Blackman MR. Effects of GH and/or sex steroids on circulating IGF-I and IGFBPs in healthy, aged women and men. American Journal of Physiology. Endocrinology and Metabolism 2006290 E1006-E1013.

26 Blackman MR, Sorkin JD, Münzer T, Bellantoni MF, BusbyWhitehead J, Stevens TE, Jayme J, O'Connor KG, Christmas C, Tobin JD, Stewart KJ, Cottrell E, St Clair C, Pabst KM \& Harman SM. Growth hormone and sex steroid administration in healthy aged women and men: a randomized controlled trial. Journal of the American Medical Association $20022882282-2292$.

27 Burman P, Johansson AG, Siegbahn A, Vessby B \& Karlsson FA. Growth hormone $(\mathrm{GH})$-deficient men are more responsive to $\mathrm{GH}$ replacement therapy than women. Journal of Clinical Endocrinology and Metabolism $1997 \mathbf{8 2} 550-555$.

28 Bloch KE, Schoch OD, Zhang JN \& Russi EW. German version of the Epworth sleepiness scale. Respiration 199966 440-447.

29 Douglass AB, Bornstein R, Nino-Murcia G, Keenan S, Miles L, Zarcone VP Jr, Guilleminault C \& Dement WC. The sleep disorders questionnaire. I. Creation and multivariate structure of SDQ. Sleep 199417 160-167.

30 Charlson ME, Pompei P, Ales KL \& MacKenzie CR. A new method of classifying prognostic comorbidity in longitudinal studies: development and validation. Journal of Chronic Diseases 198740 373-383.

31 Weaver TE \& Grunstein RR. Adherence to continuous positive airway pressure therapy: the challenge to effective treatment. Proceedings of the American Thoracic Society 20085 173-178.

32 Taaffe DR, Lewis B \& Marcus R. Regional fat distribution by dualenergy X-ray absorptiometry: comparison with anthropometry and application in a clinical trial of growth hormone and exercise. Clinical Science 199487 581-586.

33 Svendsen OL, Haarbo J, Hassager C \& Christiansen C. Accuracy of measurements of body composition by dual-energy X-ray absorptiometry in vivo. American Journal of Clinical Nutrition 199357 605-608. 
34 Münzer T, Harman SM, Hees P, Shapiro E, Christmas C, Bellantoni MF, Stevens TE, O'Connor KG, Pabst KM, St Clair C, Sorkin JD \& Blackman MR. Effects of GH and/or sex steroid administration on abdominal subcutaneous and visceral fat in healthy aged women and men. Journal of Clinical Endocrinology and Metabolism 200186 3604-3610.

35 Zapf J, Walter H \& Froesch ER. Radioimmunological determination of insulinlike growth factors I and II in normal subjects and in patients with growth disorders and extrapancreatic tumor hypoglycemia. Journal of Clinical Investigation 1981 68 1321-1330.

36 Schmid C, Krayenbuehl P-A, Bernays R-L, Zwimpfer C, Maly FE \& Wiesli P. Growth hormone $(\mathrm{GH})$ receptor isoform in acromegaly: lower concentrations of $\mathrm{GH}$ but not insulin-like growth factor-1 in patients with a genomic deletion of exon 3 in the $\mathrm{GH}$ receptor gene. Clinical Chemistry 200753 1484-1488.

37 Vgontzas AN, Papanicolaou DA, Bixler EO, Kales A, Tyson K \& Chrousos GP. Elevation of plasma cytokines in disorders of excessive daytime sleepiness: role of sleep disturbance and obesity. Journal of Clinical Endocrinology and Metabolism $1997 \mathbf{8 2}$ 1313-1316.

38 Punjabi NM, Sorkin JD, Katzel LI, Goldberg AP, Schwartz AR \& Smith PL. Sleep-disordered breathing and insulin resistance in middle-aged and overweight men. American Journal of Respiratory and Critical Care Medicine 2002165 677-682.

39 Punjabi NM \& Beamer BA. C-reactive protein is associated with sleep disordered breathing independent of adiposity. Sleep 200730 29-34.

40 Davidson TM \& Patel MR. Waist circumference and sleep disordered breathing. Laryngoscope 2008118 339-347.

41 Grunstein R, Wilcox I, Yang TS, Gould Y \& Hedner J. Snoring and sleep apnoea in men: association with central obesity and hypertension. International Journal of Obesity and Related Metabolic Disorders 199317 533-540.

42 Katzmarzyk PT, Janssen I, Ross R, Church TS \& Blair SN. The importance of waist circumference in the definition of metabolic syndrome: prospective analyses of mortality in men. Diabetes Care 200629 404-409.

43 DeFronzo RA, Ferrannini E, Sato Y, Felig P \& Wahren J. Synergistic interaction between exercise and insulin on peripheral glucose uptake. Journal of Clinical Investigation 198168 1468-1474.

44 Maeder MT, Ammann P, Münzer T, Schoch OD, Korte W, Hurny C, Myers J \& Rickli H. Continuous positive airway pressure improves exercise capacity and heart rate recovery in obstructive sleep apnea. International Journal of Cardiology 2009132 75-83.

45 Edward Shifflett D, Walker EW, Gregg JM, Zedalis D \& Herbert WG. Effects of short-term PAP treatment on endurance exercise performance in obstructive sleep apnea patients. Sleep Medicine 20012 145-151.

46 D'Ambrosio C, Bowman T \& Mohsenin V. Quality of life in patients with obstructive sleep apnea: effect of nasal continuous positive airway pressure - a prospective study. Chest 1999115 123-129.

47 Moreno CR, Carvalho FA, Lorenzi C, Matuzaki LS, Prezotti S, Bighetti P, Louzada FM \& Lorenzi-Filho G. High risk for obstructive sleep apnea in truck drivers estimated by the Berlin questionnaire: prevalence and associated factors. Chronobiology International $200421871-879$.

48 Wideman L, Consitt L, Patrie J, Swearingin B, Bloomer R, Davis P \& Weltman A. The impact of sex and exercise duration on growth hormone secretion. Journal of Applied Physiology 2006 101 1641-1647.

49 Marcell TJ, Wiswell RA, Hawkins SA \& Tarpenning KM. Agerelated blunting of growth hormone secretion during exercise may not be soley due to increased somatostatin tone. Metabolism 1999 48 665-670.

50 Kezirian EJ, Kirisoglu CE, Riley RW, Chang E, Guilleminault C \& Powell NB. Resting energy expenditure in adults with sleep disordered breathing. Archives of Otolaryngology - Head $\mathcal{E}$ Neck Surgery $2008 \mathbf{1 3 4} 1270-1275$.
51 Major GC, Series F \& Tremblay A. Does the energy expenditure status in obstructive sleep apnea favour a positive energy balance? Clinical and Investigative Medicine 200730 E262-E268.

52 Stenlöf K, Grunstein R, Hedner J \& Sjostrom L. Energy expenditure in obstructive sleep apnea: effects of treatment with continuous positive airway pressure. American Journal of Physiology 1996271 E1036-E1043.

53 Veldhuis JD, Liem AY, South S, Weltman A, Weltman J, Clemmons DA, Abbott R, Mulligan T, Johnson ML \& Pincus S. Differential impact of age, sex steroid hormones, and obesity on basal versus pulsatile growth hormone secretion in men as assessed in an ultrasensitive chemiluminescence assay. Journal of Clinical Endocrinology and Metabolism $1995 \mathbf{8 0}$ 3209-3222.

54 Veldhuis JD, Iranmanesh A \& Weltman A. Elements in the pathophysiology of diminished growth hormone (GH) secretion in aging humans. Endocrine 19977 41-48.

55 Meston N, Davies RJ, Mullins R, Jenkinson C, Wass JA \& Stradling JR. Endocrine effects of nasal continuous positive airway pressure in male patients with obstructive sleep apnoea. Journal of Internal Medicine 2003254 447-454.

56 Liu H, Bravata DM, Olkin I, Nayak S, Roberts B, Garber AM \& Hoffman AR. Systematic review: the safety and efficacy of growth hormone in the healthy elderly. Annals of Internal Medicine 2007 146 104-115.

57 Baum HB, Biller BM, Finkelstein JS, Cannistraro KB, Oppenhein DS, Schoenfeld DA, Michel TH, Wittink H \& Klibanski A. Effects of physiologic growth hormone therapy on bone density and body composition in patients with adult-onset growth hormone deficiency. A randomized, placebo-controlled trial. Annals of Internal Medicine 1996125 883-890.

58 Whitehead HM, Boreham C, McIlrath EM, Sheridan B, Kennedy L, Atkinson $\mathrm{AB} \&$ Hadden DR. Growth hormone treatment of adults with growth hormone deficiency: results of a 13-month placebo controlled cross-over study. Clinical Endocrinology 1992 36 45-52.

59 Hoffman AR, Kuntze JE, Baptista J, Baum HB, Baumann GP, Biller BM, Clark RV, Cook D, Inzucchi SE, Kleinberg D, Klibanski A, Phillips LS, Ridgway EC, Robbins RJ, Schlechte J, Sharma M, Thorner MO \& Vance ML. Growth hormone (GH) replacement therapy in adult-onset GH deficiency: effects on body composition in men and women in a double-blind, randomized, placebocontrolled trial. Journal of Clinical Endocrinology and Metabolism $2004892048-2056$.

60 Kluge M, Gazea M, Schussler P, Genzel L, Dresler M, Kleyer S, Uhr M, Yassouridis A \& Steiger A. Ghrelin increases slow wave sleep and stage 2 sleep and decreases stage 1 sleep and REM sleep in elderly men but does not affect sleep in elderly women. Psychoneuroendocrinology 200935 297-304.

61 Kluge M, Schussler P, Bleninger P, Kleyer S, Uhr M, Weikel JC, Yassouridis A, Zuber V \& Steiger A. Ghrelin alone or co-administered with GHRH or CRH increases non-REM sleep and decreases REM sleep in young males. Psychoneuroendocrinology 200833 497-506.

62 Harsch IA, Konturek PC, Koebnick C, Kuehnlein PP, Fuchs FS, Pour Schahin S, Wiest GH, Hahn EG, Lohmann T \& Ficker JH. Leptin and ghrelin levels in patients with obstructive sleep apnoea: effect of CPAP treatment. European Respiratory Journal 200322 251-257.

63 Block AJ, Wynne JW \& Boysen PG. Sleep-disordered breathing and nocturnal oxygen desaturation in postmenopausal women. American Journal of Medicine 198069 75-79.

64 Bixler EO, Vgontzas AN, Lin HM, Ten Have T, Rein J, Vela-Bueno A \& Kales A. Prevalence of sleep-disordered breathing in women: effects of gender. American Journal of Respiratory and Critical Care Medicine 2001163 608-613.

65 Martins AB, Tufik S \& Moura SM. Physiopathology of obstructive sleep apnea-hypopnea syndrome. Jornal Brasileiro de Pneumologia 200733 93-100.

66 Montserrat JM, Ferrer M, Hernandez L, Farre R, Vilagut G, Navajas D, Badia JR, Carrasco E, De Pablo J \& Ballester E. 
Effectiveness of CPAP treatment in daytime function in sleep apnea syndrome: a randomized controlled study with an optimized placebo. American Journal of Respiratory and Critical Care Medicine 2001164 608-613.

67 West SD, Nicoll DJ, Wallace TM, Matthews DR \& Stradling JR. Effect of CPAP on insulin resistance and $\mathrm{HbAlc}$ in men with obstructive sleep apnoea and type 2 diabetes. Thorax $2007 \mathbf{6 2}$ 969-974.

68 Marin JM, Carrizo SJ, Vicente E \& Agusti AG. Long-term cardiovascular outcomes in men with obstructive sleep apnoeahypopnoea with or without treatment with continuous positive airway pressure: an observational study. Lancet 2005365 $1046-1053$.

69 Coughlin SR, Mawdsley L, Mugarza JA, Wilding JP \& Calverley PM. Cardiovascular and metabolic effects of CPAP in obese males with OSA. European Respiratory Journal 200729 720-727.
70 Norman D, Loredo JS, Nelesen RA, Ancoli-Israel S, Mills PJ, Ziegler MG \& Dimsdale JE. Effects of continuous positive airway pressure versus supplemental oxygen on 24-hour ambulatory blood pressure. Hypertension 200647 840-845.

71 Pepperell JC, Ramdassingh-Dow S, Crosthwaite N, Mullins R, Jenkinson C, Stradling JR \& Davies RJ. Ambulatory blood pressure after therapeutic and subtherapeutic nasal continuous positive airway pressure for obstructive sleep apnoea: a randomised parallel trial. Lancet 2002359 204-210.

72 Ancoli-Israel S \& Kripke DF. Prevalent sleep problems in the aged. Biofeedback and Self-Regulation 199116 349-359.

Received 10 January 2010

Accepted 28 January 2010 